\title{
Visual cliff behavior of rats as a function of pattern size'
}

DORIS C. DeHARDT, California State College at Long Beach, Long Beach, Calif. 90801

On a visual cliff with $3 / 4$-in. check pattern on both sides, rats preferred the shallow side, while a significant preference for the deep side was obtained when 3-in. check pattern was used on both sides. Animals exposed to pattern-sizes which were optically equal but at different.depths showed no significant side preference. The similarity of angular size of elements at the animal's eye for $1 / 4$-in. pattern on the shallow side and 3-in. pattern on the deep side suggests the dependency of visual cliff behavior on pattern-size preference.

The need for further delineation of the importance of textural cues, including size of elements, in the visual cliff behavior of rats has been noted by Karmel (1966) and is supported both by apparent contradictions between his results and those of Walk \& Gibson (1961), and between this author's previous work (DeHardt \& Whitney, 1964) and that of Walk and Gibson. In both instances, the Walk and Gibson conclusion that textures with larger elements are preferred by rats, presumably since relatively less depth is signified, has been brought into question. The present study was specifically motivated by the data DeHardt and Whitney obtained for rats presented a 3 in.-1 in. pattern-size comparison. With the se two pattern-sizes equidistant from the glass, animals chose the 1 -in. side significantly more of ten than the 3-in. side. Given this result, it seemed reasonable to suppose that, using appropriately different patternsizes and depths on the two sides of a cliff, rats might prefer the deep side. Put another way, one might ask, does absolute or relative pattern-size preference exist in the rat, and if so, is the relative strength of this cue sufficient to overcome other cues of depth, e.g., motion parallax?

To answer this question, one group of $\mathrm{S} s$ was presented a pattern-size ( $3 / 4$ in.) for which, on the basis of previously noted size-preference evidence, animals would be expected to prefer the shallow side, while another group was presented a size condition ( $3 \mathrm{in}$.) for which a deep side preference was expected. A control group, presented optically equated pattern-sizes at different depths, was also tested.

\section{SUBJECTS}

The Ss were 73 hooded rats from the California State College at Long Beach colony. All were experimentally naive animals, approximately 120 days old. APPARATUS

The visual cliff was a replica of that described by Walk \& Gibson (Model II, 1961). Stimulus patterns were $3 / 4$ - and 3 -in. red and white checks. A 4-in. centerboard was used to ensure visual preference. Brightness was equated on the two sides of the cliff.

\section{PROCEDURE}

Food and water was available in the home cage ad lib prior to and on the test day. On each of 10 days prior to testing, Ss were handled for approximately $3 \mathrm{~min}$ and then placed in an unpainted box for $2 \mathrm{~min}$.

With the shallow side directly under the glass and the deep side 10 in. below the glass, one group of $21 \mathrm{Ss}$ was tested with $3 / 4$-in. pattern on both sides, and another group of 33 with 3-in. on both sides. For the 19 control animals, the $3 / 4$-in. pattern was directly under the glass and the 3 -in. pattern was 12 in. below the glass.

A procedure similar to that of Walk \& Gibson (1961) was used. The Ss were placed on the centerboard one at a time, with alternating direction of placement. The centerboard and both glass surfaces were cleaned before each new S was tested. A pattern preference was defined as placement, within $3 \mathrm{~min}$, of two feet on the side containing that pattern. Each $S$ was tested only once. Nineteen Ss who either failed to respond or fell off the centerboard were not included in the analyses.

\section{RESULTS}

Frequency of choice of side by condition is shown in Table 1. Animals in the $3 / 4$-in. condition descended significantly more often to the shallow side $\left(\chi^{2}=4.25, \mathrm{df}=1\right.$, $p<.05)$ and animals in the 3 -in. condition preferred the deep side $\left(\chi^{2}=6.72, \mathrm{df}=1\right.$, $p<.01)$. No significant difference in frequency of descents was found for Ss for which angular size of elements (checks) was equated $\left(x^{2}=47, \mathrm{df}=1\right)$.

\section{DISCUSSION}

The obtained results clearly indicate that rats will enter the deep side of a visual cliff

Table 1

Frequency of Choice of Side

\begin{tabular}{|c|c|c|c|}
\hline Condition & $\mathbf{N}$ responding & $\begin{array}{l}\text { Frequenc } \\
\text { Shallow }\end{array}$ & $\begin{array}{c}\text { y of side } \\
\text { Deep }\end{array}$ \\
\hline $3 / 4$-in. & 19 & 15 & $4 *$ \\
\hline 3-in. & 18 & 3 & $15^{* *}$ \\
\hline control & 17 & 11 & 6 \\
\hline
\end{tabular}

$* p<.05$

$* * p<.01$ when pattern-size alone is manipulated in an appropriate manner. The critical variable in the appropriate manipulation of pattern-size is, of course, angular size of elements at the animal's eye. Assuming, as did Walk \& Gibson (1961), that the animal's eye is $1 \mathrm{in}$. above the centerboard, the visual angles subtended by the $3 / 4$ - and 3 -in. pattems on the shallow side were $8 \mathrm{deg} 32 \mathrm{~min}$ and $30 \mathrm{deg} 58 \mathrm{~min}$, respectively, and on the deep side were $2 \mathrm{deg} 52 \mathrm{~min}$ and $11 \mathrm{deg} 19 \mathrm{~min}$, respectively. The similarity of retinal sizes of the two significantly preferred alternatives, the $3 / 4$-in. pattern on the shallow and the 3 -in. pattern on the deep, suggests that the rat's choice of side on the visual cliff may be indicative of a pattern-size preference and not of visual depth discriminability.

The results of some previous studies, for example Karmel's (1966), are clearly consistent with those reported here. Karmel found that rats preferred the smaller-sized elements when two different texture-sizes were each placed directly under the glass. It is significant that the smallest size he used was 1 in. In addition to such obviously consistent evidence, earlier findings seemingly difficult to interpret are reasonable in light of the present analysis. For example, DeHardt \& Whitney (1964) reported no preference for either side for rats presented a 3 -in. check pattern $3 \frac{11}{4}$ in. and $46 \% \frac{1}{2}$ in. below the centerboard in an enclosed visual cliff. The angular size of elements at the animal's eye on the shallow and deep sides in that instance was $35 \mathrm{deg} 13 \mathrm{~min}$ and $3 \mathrm{deg}$ $37 \mathrm{~min}$, respectively, then. Since these angular sizes are similar to those seldom preferred in the present study, the contribution of absolute pattem-size preference to visual cliff performance is suggested.

Further work on the relative importance of pattern-size preference in visual cliff situations remains to be done, however. Results such as those reported by Lore, Kam, \& Newby (1967) are possibly contradictory to those reported here. In their study, a group of monocular rats preferred the shallow side when a 2 -in. pattern was presented at depths of 2.27 and 20 in. In other words, the side whose angular size of elements was $31 \mathrm{deg} 27 \mathrm{~min}$ was preferred to that with 5-deg 26-min elements. To properly evaluate these, as well as the DeHardt and Whitney data, the necessity of determining whether absolute or relative pattern-size preference is operative and how pattern-size preference interacts with other cues in visual cliff situations is evident.

Studies currently in progress involve utilization of many more pattern-sizes and pattern-size combinations, and attempts to manipulate pattern-size preference and thus cliff side choice by manipulation of environmental history. 


\section{REFERENCES}

DeHARDT, D. C., \& WHITNEY, D. L. Depth discrimination in rats on visual cliffs. Perceptual \& Motor Skills, 1964, 19, 423-426.

KARMEL, B. Z. Randomness, complexity, and visual preference behavior in the hooded rat and domestic chick. Journal of Comparative \& Physiological Psychology, 1966, 61, 487-489.

LORE, R., KAM, B., \& NEWBY, V. Visual and nonvisual depth avoidance in young and adult rats. Journal of Comparative \& Physiological Psychology, 1967, 64, 525-528.

WALK, R. D., \& GIBSON, E. J. A comparative and analytical study of visual depth perception. Psy chological Monographs, 1961, 75 (15, Whole No. 519).

NOTE

1. I wish to thank Ronald Brower for his assistance during various stages of the study.

\section{Temporal uncertainty of reinforcement'}

\author{
FRED L. ROYER, Veterans Administration \\ Hospital, Brecksville, Ohio 44141
}

Three CSs had a duration of $5 \mathrm{sec} . \mathrm{CS}+\mathrm{C}$ was always reinforced with shock 1 sec after termination; $C S$ - was never reinforced; and $C S+U$ was reinforced $75 \%$ of the trials with reinforcement occurring randomly 1, 3, or $5 \mathrm{sec}$ after CS offset. Mean heart rate increments were: $C S+C, 9.7 \mathrm{bpm} ; C S-$, $-2.5 \mathrm{bpm} ; \mathrm{CS}+U, 3.8 \mathrm{bpm}$. Mean leg flexion latencies for $\mathrm{CS}+\mathrm{C}$ were $2.9 \mathrm{sec}$, and for $C S+U, 4.2 \mathrm{sec}$. Cardiac URs for $C S+U$ are diminished. Data suggest more resistance to extinction for $\mathrm{CS}+U$.

In a study of Pavlovian discriminative conditioning of dogs using CSs differing in their reliability as predictors of reinforcement, Royer (1969) found that a CS $(\mathrm{CS}+\mathrm{C})$ which was consistently reinforced with shock elicited greater heart-rate change and shorter leg-flexion latencies than one reinforced inconsistently on a temporal basis (CS+U). All CSs were $6 \mathrm{sec}$ in duration. $\mathrm{CS}+\mathrm{C}$ was reinforced immediately upon termination (delay paradigm). Since reinforcement of $\mathrm{CS}+\mathrm{U}$ could be immediately after termination or 2 or $4 \mathrm{sec}$ afterward (mixed delay and trace paradigms) there is a possibility that the offset of $\mathrm{CS}+\mathrm{U}$ was an informative event (Egger \& Miller, 1963), which in effect became the CS.

The purpose of this study was to replicate the previous one using the trace paradigm for each CS+

\section{SUBJECTS}

Four experimentally naive female Beagle dogs were used as Ss. They were 11 months old at the beginning of conditioning. APPARATUS

Heart rate, flexion response, and intensity of shock current were recorded by means of a Grass Model 7P polygraph. A digital logic system provided the programming of both CSs and USs.

\section{PROCEDURE}

The acquisition data used in the analyses are for the 15 days beginning with the 8 th and continuing through the 22 nd day of conditioning. Extinction trials were carried out over a 4-day period.

Each CS was 5 sec in duration and was presented eight times daily in a fixed order with a $2 \cdot \mathrm{min}$ interstimulus interval. In order of occurrence, the CSs were (1) CS+C, a $61-\mathrm{dB}$ tone of $4500 \mathrm{~Hz}$, followed, 1 sec after termination, by an electric shock of $1 \mathrm{sec}$ duration; (2) CS-, a flashing light never reinforced; (3) $\mathrm{CS}+\mathrm{U}$, a $61-\mathrm{dB}$ tone of $2500 \mathrm{~Hz}$ followed by one of four reinforcement consequences-no shock for $25 \%$ of the trials, and shock either $1 \mathrm{sec}, 3 \mathrm{sec}$, or $5 \mathrm{sec}$ after CS termination on remaining trials.

The US was presented to the shaved left foreleg. Electrode gel was used to ensure minimal resistance. US intensity was adjusted to produce a vigorous flexion without at the same time producing generalized motor excitement. Alternating current and voltage were monitored and the power was computed; the intensity varied from 12 to $20 \mathrm{~mW}$.

\section{RESULTS}

An analysis of variance was made of the daily change in heart rate (heart rate during CS minus heart rate pre-CS) for the 15-day conditioning period. Mean heart rate changes were: $\mathrm{CS}+\mathrm{C}, 9.7$ beats per minute (bpm); CS-, -2.5 bpm; CS+U, 3.8 bpm. These means are significantly different $(F=47.83, \mathrm{df}=2 / 6, \mathrm{p}<.01)$. The appropriate $t$ tests (McNemar, 1962, p. 345) showed that the means of each possible pair differed significantly.

The percentage of trials in which leg flexion responses occurred were: $\mathrm{CS}+\mathrm{C}$, 85.6\%; CS-, 5.0\%; CS+U, 81.2\%. A probability distribution of the latencies of flexion responses is shown in Fig. 1. The differences in latencies are clear; flexion during the $\mathrm{CS}+\mathrm{C}$ is more probable during the first half of the CS, while flexion during the $\mathrm{CS}+\mathrm{U}$ is more probable late in the CS. Mean latencies for $\mathrm{CS}+\mathrm{C}$ were $2.9 \mathrm{sec}$, for $\mathrm{CS}+\mathrm{U}$ were 4.2 sec.

Figure 2 shows the unconditional heart rate levels for the various reinforcement alternatives. Because of the time intervals elapsing between termination of the $\mathrm{CS}$ and onset of US, levels were used rather than change scores. The UR for $\mathrm{CS}+\mathrm{C}$ is greater than that for $\mathrm{CS}+\mathrm{U}(1)$, the condition under which the US was presented in the same temporal relation as for the $\mathrm{CS}+\mathrm{C}$ $(F=282.00, \mathrm{df}=1 / 3, \mathrm{p}<.01)$. The heart rate during the period immediately following the $\mathrm{CS}+\mathrm{U}$ when no reinforcement was presented (Condition 0 ) is also significantly greater than that for the $\mathrm{CS}$ - during the post-CS period. Furthermore, it will be seen that the UR may be different, depending upon the time interval after the $\mathrm{CS}$ in which the US occurred ( $F=6.88, \quad \mathrm{df}=3 / 9$, $\mathrm{p}<.05)$. The following pairs of means were significantly different: 0,$1 ; 0,2 ; 2,3$. It is clear from these data that even the unconditional response is affected by the temporal uncertainty of the US.

The results of the extinction procedure were evaluated by an analysis of daily mean changes in heart rate. There were no significant differences $(F=2.94, d f=2 / 6$, $p>.05)$ among the means for changes in the stimulus periods (CS period minus pre-CS period). There were, however, significant differences among the means $(\mathrm{F}=6.88$, $\mathrm{df}=2 / 6, \mathrm{p}<.06)$ for the post $\mathrm{CS}$ periods (post-CS minus CS). The mean changes in beats per minute were: $\mathrm{CS}+\mathrm{C}, 1.8$; $\mathrm{CS}+\mathrm{U}$, $8.8 ; \mathrm{CS}-,-3.4$. The $t$ tests for ndividual comparisons indicate that $\mathrm{CS}+\mathrm{U}$ and $\mathrm{CS}-$ are significantly different but $\mathrm{CS}+\mathrm{C}$ is not 